\title{
O DESENVOLVIMENTO DA ATIVIDADE VOLUNTÁRIA NA ONTOGÊNESE: POSTULAÇÕES DOS TEÓRICOS DA PSICOLOGIA HISTÓRICO-CULTURAL
}

Ana Paula Alves Vieira ${ }^{1}$ Zaira Fátima de Rezende Gonzalez Leal ${ }^{2}$

\section{INTRODUÇÃO}

Entendemos a atividade voluntária como uma atividade de gênese histórica e cultural, resultante do domínio de instrumentos físicos e mentais. De acordo com Vygotsky e Luria $^{1}$ (1996) é por meio da apropriação dos instrumentos culturais (todas as produções da humanidade, como, por exemplo, os instrumentos de trabalho, a arte, a algebra e a escrita) que as funções psicológicas superiores se desenvolvem e são capazes de promover a autorregulação do comportamento. O domínio desses instrumentos é necessário para o domínio do próprio comportamento no desenvolvimento ontogenético, tendo a linguagem um papel fundamental nesse processo. O domínio desses instrumentos está relacionado com a capacidade de criar e se dirigir a um objetivo estabelecido, sendo essa a característica essencial da atividade voluntária. Vigotski ${ }^{1}$ apresenta o autodomínio como um dos conceitos fundamentais para o desenvolvimento humano, dessa forma, para a Psicologia Histórico Cultural (PHC) o desenvolvimento da atividade voluntária é fundamental no desenvolvimento da personalidade.

\section{MÉTODOS}

Este trabalho é parte da pesquisa de mestrado vinculada ao núcleo de Psicologia da Universidade Estadual de Maringá (UEM) ainda em andamento e objetiva apresentar como os teóricos fundadores da PHC- L. S. Vigotski (1896-1934), A. R. Luria (1902-1977) e A. N. Leontiev (1903-1979) - entendem o fenômeno referente à atividade voluntária.Foi realizado uma revisão bibliográfica nas obras clássicas dos autores mencionados a fim de conceitualizar a atividade voluntária e como se dá seu desenvolvimento na ontogênese.

${ }^{1}$ Docente Faculdade da Cidade de Coromandel (FCC), mestranda Universidade Estadual de Maringá (UEM). Email de contato: avieira.ap@gmail.com.

${ }^{2}$ Docente Universidade Estadual de Maringá (UEM). 


\section{RESULTADOS E DISCUSSÃO:}

\subsection{Postulações de Vigotski acerca do domínio do comportamento}

Para Vygotsky²assim como o domínio da natureza não pressupõe a abolição das leis básicas da natureza, o domínio do próprio comportamento também não, mas sim uma subordinação dessas leis. A lei básica da conduta, de acordo com o autor, consiste na lei de estímulo-resposta, dessa forma, a dominação do comportamento corresponde a uma dominação dos estímulos.

\subsection{A atividade voluntária à luz da Teoria da Atividade de Leontiev}

Leontiev 3 propôs a "atividade" como objeto de estudo da PHC e a "ação" como unidade de análise. Sobre a atividade voluntária, $\mathrm{O}$ autor relaciona seu desenvolvimento com o desenvolvimento da esfera motivacional.

\subsection{A atividade voluntária desde a neuropsicologia de Luria}

Luria ${ }^{4}$ desenvolve a tese de Vigotski acerca das ações voluntárias e busca seu desenvolvimento no cérebro. A unidade de análise da Neuropsicologia, é o fator - o mecanismo psicofisiológico da ação e das operações. Um fator é o resultado do trabalho que realiza uma ou mais zonas altamente especializadas do cérebro. O fator relacionado à atividade voluntária é o de Regulação e Controle, produto do sistema funcional do terceiro bloco, que corresponde à área frontal do cérebro.

\section{CONSIDERAÇÕES}

Nas obras eleitas para análise, identificamos que Vigotski postula sobre a voluntariedade, o autocontrole, o autodomínio e a autorregulação, mas não aponta uma distinção entre esses processos e também não assinala definições claras. Postula sobre a mediatizaçãodos signos no controle do comportamento. Leontiev acrescenta a Teoria da atividade, explicando como a criança aprende a se regular através de atividades que desenvolve exteriormente. Luria aprofunda na análise dos mecanismos efetores da atividade, com a neuropsicologia.

\section{REFERÊNCIAS}


1. Vygotsky, LS., Luria, A.R. Estudos sobre a história do comportamento: o macaco, o homem e a criança. Porto Alegre: Artes Médicas, 1996.

2. Vygotsky LS.Obras escogidas III: Problemas del desarrollo de la psique. Madrid: Machado Grupo de Distribución; 2012.

3. Leontiev AN. El desarrollo psicológico en la edad preescolar. In: Solovieva Y, Quintanar L. Antología del desarrollo psicológico del niño en edad preescolar. México: Trillas; 2010. p. 1726.

4. Luria AR. Las funciones corticales del hombre. 3 ed. México: fontamara; 2015. 